\title{
Mirror Image of Yunnan: Innovative Strategy of Yunnan Image in Entertainment Programs
}

\author{
Shao Yang \\ School of music and dance, Qujing Normal University, Qujing, Yunnan 655011
}

Keywords: entertainment program; Yunnan image; innovation strategy

\begin{abstract}
Yunnan is located in the southwest of China, known for its beautiful, rich, magic is famous in the world, the outside world has always been known as the "mystery", attracts visitors from all over the world. The world-famous Jinsha River, Nu River, the Lancang river flows through here side by side, Xianfeng Canyon rivers and streams have a long history, arranged in a crisscross pattern, lakes dotted hot, creating a beautiful piece of paradise. Picturesque Yunnan, through entertainment programs, is to create a beautiful brand, through television programs, more unknown places in Yunnan gradually known by people, formed a very good brand strategy. Therefore, this article through the entertainment program in Yunnan image analysis, to explore the entertainment program in Yunnan image innovation strategy.
\end{abstract}

In recent years, Yunnan has broadcast a reality show "soldier assault", "cultural educational programs Chinese Congress", "lantern riddles of high-quality documentary classic human geography" and many other entertainment programs are also competing in Yunnan, a Yunnan film, the beautiful scenery is known, Yunnan is also relying on entertainment to create a a beautiful city name card, make the popular image of Yunnan.

\section{Positive significance, entertainment on the economic development of Yunnan}

For a long time, Yunnan tourism slogan "colorful Yunnan, holiday paradise" people, the mention of Yunnan, people will think of Dali, the beautiful scenery of Kunming, however, in the reality of Yunnan tourism is to eat their resources impression, thank God for blessing to the rich tourism resources in Yunnan, but these precious richly endowed by nature. The resources need to cherish and protect people, predatory exploitation can not be extensive. Yunnan as a minority in numerous provinces, rich ethnic customs, behind every ethnic customs have rich national culture, an important wealth of the intangible cultural heritage is also in Yunnan, for example, as everyone knows the torch festival, Yi Dai Songkran and peacock dance culture, can show through entertainment to the country show the local characteristics of Yunnan, thereby expanding the income of tourism resources, promoting the economic development of Yunnan [1].

City brand represents the image of a place, Yunnan is located in remote, although there are abundant natural resources and beautiful scenery, but not known it is difficult to realize its own value, the development direction of image of a city, a good city image can attract people's eyes. The TV show of Yunnan image and communication, to enhance the internal cohesion and external attraction, stimulate the body to increase peoples awareness and innovation awareness, and promote the realization of Yunnan development strategy to achieve the overall economic and social development, has the direction and target of action. Development is the hard truth, reform is the motive force, stability is a prerequisite for development and reform. As a popular program, entertainment programs are widely spread, which can guide people's value orientation and direction of public opinion. It is one of the important ways of city brand building. Vigorously promote national economic and social development strategy, drive industrialization with informatization, radio play advantage, to achieve leapfrog development of social productive forces is the strategic initiatives related to the overall situation of socialist modernization construction. Relying on a variety of entertainment programs, it has the advantages of providing more convenient information dissemination and advisory services for the economic and social development of the province, as 
well as the popularization of science and technology, culture and education. In the implementation of the strategy of "rejuvenating the country through science and education", "enriching the people and promoting Yunnan", building a "green economy strong province", "a big province of national culture" and "international thoroughfare", we can accomplish a great deal [2].

\section{The image of Yunnan in entertainment programs}

Since the "tongue on China" after the broadcast, won the people's favorite, let people know more delicious snacks, like ham, Dali dairy fan, Nuo Deng Shiping tofu, Kunming fried chicken...... Some of Yunnan's special diets are burning, and countless people are watching it while they are drooling. Due to the regional particularity and national diversity, there are countless kinds of snacks in Yunnan, and each nation has its own unique diet. The rice noodle buds, Shiping tofu Jianshui, Mengzi are refined and known; Northeast Yunnan is the only way which must be passed into the Central Plains area, strong historical heritage, Braised Tofu with Vegetables, buckwheat jelly, crisp red bean are there local snacks; Lijiang Lijiang Baba, eight bowl is not to be missed, there are not many were the world to explore, so some people say that if you want to taste the delicacy of Yunnan, must always live in here. Delicious food reminds people of appetite, but also let people re understand the image of Yunnan cuisine [3].

With the development of economy, the tourism economy has become an important force in urban development, so that the city can attract foreign investment while going out, so that more people recognize the characteristics of Yunnan. From the Yunnan World Horticultural Exposition held in the provincial capital of Kunming, to the "debauch" of the Dali scenic spot; from Lijiang, Shuicheng plateau magic "Shangri-La" - Zhongdian, the peacock dance from Xishuangbanna; "the best in all the land Yuanmou earth forest wonders" Shilin, rare in the world in different poses and with different expressions, to the "Sanjiang" and flow. Narrow water dragon Tiger Leaping Gorge river...... These countless landscapes highlight the characteristics of Yunnan, and today's entertainment programs increasingly focus on reality shows, and Yunnan has become a favorite place for reality shows. In "where is the father and son a" adventure reality show, star dad and the kids came to Yunnan, attracted by the beautiful scenery of Yunnan, have expressed a fairyland, through the show, the audience saw the local people of Yunnan green mountains and rivers and passion, make the audience feel better in Yunnan tourism characteristics. Through entertainment programs, Yunnan can create a distinctive image of tourism, and then the food and natural scenery as the starting point to build a tourist city. For example, Weishan as the famous delicacy Town, known as "eating in Weishan" reputation, including all kinds of snacks is a long history, variety, taste delicious, in 2014 was named "Chinese gourmet Association Chinese snack village". Weishan county Party committee and government to further realize the strategic goal of "Xing Wei brigade to" cultivate tourism as a pillar industry of the Weishan delicacy and snacks as a starting point to create highlights and, since 2011, has successfully held five sessions of "seeking Nanzhao taste Weishan Dali Weishan snack festival. In the "13th Five-Year" period, Weishan also vigorously develop leisure sports and health products, tourism products, and actively promote the development of special tourism products, composite products system in tourism products to tourism, leisure, sports and health, special tourism products, transformation. Accelerating the development and construction of tourism products focusing on tourist towns, tourist towns, tourist villages and tourist camping sites. To transform, upgrade, improve quality and efficiency as the main line, to promote tourism products to tourism, leisure, sports, vacation and equal emphasis on change, to meet the diverse, multi-level tourism consumption demand. With the project construction as the carrier, we can effectively promote the construction of composite products, hotel accommodation, tourism culture, national culture and other tourism projects, and realize the transformation and upgrading of Weishan tourism product system. By creating tourism characteristic cities, Yunnan can develop its characteristic economy according to local conditions [4].

Through entertainment programs, we can see the blue sky and the clear lake of Yunnan. Yunnan, as a national key tourist city, must cherish and protect the natural resources of the city. Yunnan Cangyuan through the construction of "smiling City, entrepreneurial city, forest city, clean city" 
Four city one of the beautiful border city to enhance the brand image of the city, in order to protect the ethnic wa traditional architectural style, publicity personality, Zhang Xian city city characteristics, enhance the taste of the city as the goal, in order to comprehensively promote the city, national style the characteristics of tourism development, brand positioning, in accordance with the "building a painting, a King Street area, the wa Mountain Park" concept, the county primary and secondary roads on both sides of the eyes of building "tailor" and the transformation, the full implementation of city landscape renovation project, and strive to build a set of natural, ornamental, culture as a whole, urban tourism with regional characteristics, rich culture, ecological livable. In this way, the publicity of entertainment programs and Yunnan green ecological construction complement each other, and better shape the green ecological image of Yunnan.

\section{Innovative strategies of shaping Yunnan image in entertainment programs}

Now on the market of the entertainment to funny and funny dragons and fishes jumbled together, mostly, lack of substance, the audience to watch the program often show a smile, for the landscape, the characters will not have a great impression, which is not conducive to the program publicity, service function, TV function, entertainment function has not been fully reflected. Therefore, in Yunnan province to enhance the brand image, must take the program as the fundamental, follow the radio and television law and the law of the market economy, earnestly frequency, channel planning based on the protection of Yunnan ethnic characteristics, fully tap the Yunnan radio and television resources, according to the factors of production resource allocation of capital, human capital, science and technology in three aspects. The introduction of excellent entertainment to expand publicity, publicity ideas constantly updated, improved methods of publicity, enhance the publicity of art. Strengthen publicity for publicity, enhance the effect, to further promote internal propaganda, expand publicity. To strengthen foreign language programs and national programs from human, financial, material and other aspects, expand publicity language, attract overseas audience to have the authority of the state and has the characteristics of Yunnan program. Yunnan rich ethnic culture as a source of creativity, go nationalization and popularization, quality of the road, to improve the quality of programs, and gradually establish a socialist market economic system and orderly competitive radio and television programs to promote the circulation system, broadcast television drama, documentaries and variety program creation, production, circulation and spread to scale, the direction of intensive development [5].

Now many domestic entertainment is to buy his country's copyright or plagiarism outstanding programs, excellent programs or original ethnic characteristics is less and less, as Yunnan rich ethnic customs in the region, should make full use of local resources advantage, the national characteristics and modern elements combine to produce have a unique style of entertainment. In "where is the father" in Fujian Fujian Dongxiang Pintan island as an example, here is the winding coastline a glance in the past have a panoramic view of the soft sands and the blue sky, the old stone house on the island, the mountain and the sea, well-proportioned scattered on the beach, people leisurely and comfortable living island life, yearning. And Yunnan can also dig out the local ancient culture, keep pace with the times, with the entertainment program platform to carry forward the characteristic culture of Yunnan.

When Yunnan in entertainment publicity of the image of the city, but also to spread advanced culture, promote social justice, promote positive energy, not for ratings and crudely made, the spread of bad information, some vulgar kitsch. Entertainment in the image of the city on behalf of the city residents overall quality of civilization, has the guiding role of public opinion, so Yunnan should grasp the construction of decision management and supervision, supervision and inspection system, to make the audience marketing management, coverage and transmission management, further improve the management system, establish and improve the information transfer and publicity rating, audience feedback, review and approval of annual inspection program, the corresponding reward, constraints, rewards and punishment system, the real form and stimulate the vitality of normative behavior, not only to meet the needs and strengthen guidance, both to promote prosperity and good situation of healthy development[6]. 


\section{Conclusion}

The beauty of Yunnan through the mirror, relying on television programs to show, and expand publicity and attraction, and entertainment as the popular form of propaganda, has become an important and important position in ideology and culture, is an important part of Chen of the national economic and social development. Therefore, Yunnan should fully tap the resources of film and television programs, make good use of the exposure of entertainment programs, to enhance the publicity of Yunnan image, so that more people remember the charm of Yunnan.

\section{Acknowledgement}

Project supported by Qujing Normal University: "mirror Yunnan: innovative strategy of Yunnan i mage in entertainment program" 2015QN017

\section{References}

[1] Lu Y K, Chen H F, Zhang H Y, et al. Investigation and Preliminary Analysis of Rural and Town Building Damages of Yunnan Ludian Ms6.5 Earthquake[J]. Advanced Materials Research, 2015, 1065-1069(3):1464-1468.

[2] Liu G Q, Lu R W. The image field rotation of the auto-guide unit of the solar telescope in Yunnan Observatory[J]. Publications of the Yunnan Observatoty, 2003, 68(4):págs. 555-562.

[3] Chi-Kang H E. On innovation strategies of the tourism marketing management in Yunnan[J]. Tourism Research, 2010.

[4] Nan B, Wang J, Yang S. The Image Previous Process in Study the Habitat Fragmentation of Yunnan Snub-nosed Monkey[J]. Journal of Guizhou University, 2003, 20:190-195.

[5] Yin B, Ding S, Huang J, et al. Research on SWOT Analysis for Technical Innovation Strategy of a Yunnan-Stationed Mining Enterprise[C]// International Conference on Economy, Management, Law and Education. 2017.

[6] Wang J, Wu X. An experimental comparison of ETM+ image geometric correction methods in the mountainous areas of Yunnan Province, China[C]// International Symposium on Digital Earth. International Society for Optics and Photonics, 2010. 